\title{
Food Consumption of Marathon and Founder Runnes, After Dietary Intervention, Petrolina - PE
}

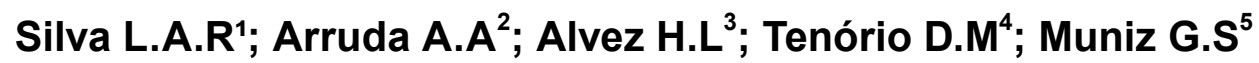 \\ ${ }^{1,2}$ Nutrition's Student- UFPE (Campus Recife); ${ }^{3,4}$ Nutritionists - UPE (Campus Petrolina), ${ }^{5}$ Teacher/ \\ Researcher of Nutrition Departament- UFPE (Campus Recife)
}

\section{ABSTRACT}

A Introduction: Food behavior is determined by interactions between physiological, psychological, genetic and environmental factors, besides being related to the nutritional status of the individual, represented by the sum of the interaction of somatic and functional elements responsible for nutrient absorption and adequacy of the physiological needs. Objective: To evaluate the dietary intake related to the physical performance of athletes, dietitians and marathon runners of Petrolina before and after the nutritional intervention. Methodology: The population was 10 athletes of the Petrolinense Association of Athletics (APA). Food intake was performed by the Food Frequency Questionnaire (FFQ) and the $24 \mathrm{~h}$ recall $(\mathrm{R} 24 \mathrm{~h})$. Calories, macronutrients and micronutrients were quantified before and after nutritional intervention. The consumption analysis was performed by dietwin. Results and Discussion: The energy consumed by the athletes was lower than the recommendation ( $p=0.015)$; the carbohydrates and lipids consumed also presented inferior to the recommendations. In addition, only the protein did not differentiate between the consumed and the recommendation $(p=0.07)$. No changes were observed in relation to consumption and recommended (after intervention) at calcium and sodium levels $-p>0.05$. There was also no statistical difference between the intake of saturated fat ( $p$ $=0.856$ ) and fibers $(p=0.887)$. The lower consumption of energy and carbohydrates by the athletes according to the physical modality practiced, can affect the yield. The lipid intake lower than the recommendations was related to the concern in reducing the weight and to combat the increase of the subcutaneous fat, altering the corporal composition. Conclusion: It was observed that the evaluation and intervention is important so that the athlete's menus is adequate and, consequently, avoid the installation of a systematically deficient energy picture that can negatively reflect on health, affecting the athletic performance.

*Correspondence to Author:

Silva L.A.R

Nutrition's Student- UFPE (Campus Recife)

How to cite this article:

Silva L.A.R; Arruda A.A; Alvez H.L; Tenório D.M; Muniz G.S. Food Consumption of Marathon and Founder Runnes, After Dietary Intervention, Petrolina - PE. International Journal of Sports Medicine and Rehabilitation, 2018, 1:4

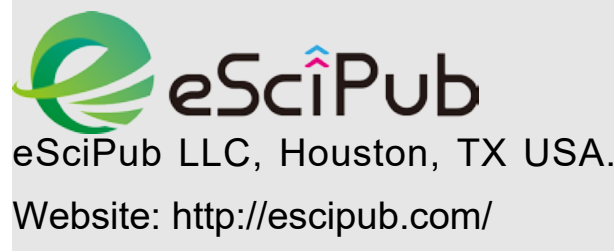

Keywords: Athletes; Performance; Energy; Nutrition 